\title{
Institutional design and regime effectiveness in transboundary river management - the Elbe water quality regime
}

\author{
I. Dombrowsky \\ UFZ, Helmholtz Centre for Environmental Research, Leipzig, Germany \\ Received: 4 May 2007 - Published in Hydrol. Earth Syst. Sci. Discuss.: 13 June 2007 \\ Revised: 11 December 2007 - Accepted: 3 January 2008 - Published: 4 February 2008
}

\begin{abstract}
The literature on transboundary river management suggests that institutions play an important role in bringing about cooperation. However, knowledge about how such institutions should be designed in order to do so remains limited. One way to learn more about adequate institutional design is to assess the effectiveness of existing regimes, and to trace the causal relationships that lead to the respective outcomes. In order to gain further insights into the relationship between institutional design and regime effectiveness, this paper presents a study on the water quality regime of the International Commission for the Protection of the Elbe (ICPE). The analysis is based on a review of pertinent documents and ten qualitative interviews with Czech and German Commission members and NGO representatives. Particular emphasis has been put on determining the ICPE's specific contribution and the no-regime counterfactual as well as on the perceived expediency of the institutional arrangements.

The study shows overall that the countries were relatively successful in improving water quality in the Elbe basin. However, this outcome can only partly be attributed to the ICPE itself. Furthermore, the ICPE's contribution towards achieving the various goals varied significantly between the different areas of activity: it was relatively significant where the main responsibility for action lay with the public authorities, such as in the area of wastewater treatment and the establishment of an international alarm plan and model, but was practically non-existent in the reduction of non-point pollution from agriculture, where success depended on the behavior of individual private actors (farmers). The commission contributed towards problem solving by serving as a forum for the joint identification of priorities for action from a basin-wide perspective. The resulting international obligations increased the power of national water administra-
\end{abstract}

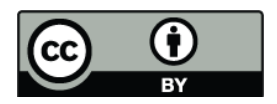

Correspondence to: I. Dombrowsky (ines.dombrowsky@ufz.de) tions and their access to funds. At the same time, the Commission's reporting to the public served as an enforcement mechanism. From a methodological point of view, the paper highlights the opportunities and limitations of a combined quantitative and qualitative approach to determining regime effectiveness.

\section{The problem}

In recent years, a discourse has emerged on conflict and cooperation in the management of international transboundary rivers (Gleick, 1993; Rogers, 1993; Waterbury, 1994; Barrett, 1994; Bernauer, 1997; Wolf, 1998; Gleditsch et al., 2006; Zeitoun and Warner, 2006). In this context it has been observed that, despite predictions of conflict, quite a number of international river basins have seen the establishment of international agreements and also the setting up of river basin organizations (Wolf, 1998; UNEP, 2002; Dombrowsky, 2007a). Furthermore, it has been suggested that institutions are an important explanatory variable with regard to cooperation (e.g. Wolf et al., 2003). At the same time, knowledge about adequate institutional design for the management of international rivers remains limited (Bernauer, 1997). While some progress has been made in explicating the negotiation strategies and external conditions under which the formation of international water institutions or regimes can be expected (LeMarquand, 1977; Durth, 1996; Marty, 2001; Espey and Towfique, 2004; Sadoff and Grey, 2002; Song and Whittington, 2004; Dinar, 2006; Lindemann, 2006; Dombrowsky, $2007 \mathrm{a}, \mathrm{b}$ ), there is still no full convergence of opinion among the various authors. Furthermore, the establishment of an international water regime does not provide any guarantees that it will ultimately contribute towards problem solving. Thus, if ultimately we want to learn more about adequate institutional design we also need to study the effectiveness of the respective international regime and to trace the underlying

Published by Copernicus Publications on behalf of the European Geosciences Union. 
causal effects (e.g. Underdal, 1992; Bernauer, 1995; Helm and Sprinz, 2000).

However, rigorous studies on the effectiveness of international water regimes remain rare .(Bernauer, 2002). Rangeley et al. (1994) claim that many international water treaties in Africa have remained "paper tigers", but the evidence remains at an anecdotal level. Other authors point out the obstacles faced in implementing the water-related provision in the Israeli-Jordanian Peace Treaty of 1994 or the 1995 Oslo B Agreement among Israelis and Palestinians (e.g. Edig, 2001; Dombrowsky, 2003; Fischhendler, 2007). Fischhendler et al. (2004) analyze recent difficulties in implementing the 1944 Boundary Waters Treaty concluded between Mexico and the United States.

An exception, both in terms of more rigorous effectiveness analyses and in terms of the relative success of the underlying regime, is the 1987 Rhine Action Program of the International Commission for the Protection of the Rhine (ICPR) which has been hailed as a success story of international river cooperation (Durth, 1996; Bernauer and Moser, 1996; Gurtner-Zimmermann, 1998; Holtrup, 1999; Verweij, 2000). In this context, the literature threw up a number of factors that are considered as drivers for the perceived success of ICPR, including: a joint vision; a phased approach with achievable targets; technical dialogue among those responsible for implementation; implementation at the national level; monitoring through publication of national reports; admission of NGOs; a small secretariat; and the non-binding character of the action program (e.g. Holtrup, 1999). However, even in the case of the Rhine the relationship between institutional design and outcome is not entirely clear. Bernauer and Moser (1996) point out the fact that much of the success can be attributed to independent activities at national level. Gurtner-Zimmermann (1998), who explicitly studied the effectiveness of the Rhine Action Program, did not relate the outcome to the institutional set-up. Holtrup (1999) on the other hand did not establish the causal relationship between institutional design and regime outcomes. This indicates that further research on the relationship between institutional design and regime effectiveness is warranted, not only for the Rhine but also beyond this river basin.

In order to gain further insight into the relationship between institutional design and regime effectiveness, this paper presents a study of the water quality regime of the International Commission for the Protection of the Elbe (ICPE). The Elbe has been selected because the Elbe regime draws heavily on the Rhine model (Holtrup, 1999). However, in contrast to the Rhine, the Elbe riparian countries are characterized by greater economic inequality. Hence, the Elbe can be considered a test case for whether it was possible to transfer the Rhine model to more asymmetric economic conditions. The Elbe thus represents an example of an upstreamdownstream water quality conflict, where the upstream country is in an advantageous situation from a hydrological point of view but the downstream country is so from an economic point of view. Also, the literature on the ICPE remains sparse and, to the author's knowledge, no rigorous study of the effectiveness of the ICPE water quality regime has so far been carried out. The study looks at the period 1990-2004/5 that is, before the substantive implementation of the European Union Water Framework Directive (WFD) in the Elbe Basin and the reform of the ICPE - in order to assess the effects of voluntary cooperation mechanisms (for an assessment of the effects of the WFD on international cooperation in the Rhine and Elbe Basins, see Möllenkamp, (2007)).

Against this background, this study seeks to contribute to the literature on transboundary water management by analyzing the expediency of the transboundary institutional arrangements in the Elbe basin, based on an effectiveness analysis and on tracing the causal relationships that led to the respective outcomes. Section 2 will introduce the underlying theory and methodology for measuring and explaining regime effectiveness. Section 3 will describe the Elbe water quality regime. Section 4 will analyze the effectiveness of the Elbe water quality regime. Section 5 will explain the outcome and Sect. 6 will draw conclusions.

\section{Theory and methodology}

\subsection{Measuring and explaining regime effectiveness}

One way to determine whether the institutional design of an international regime is adequate is to assess its effectiveness. In this context, institutions can be understood as the formal and informal "rules of the game" (e.g. North, 1990). The term "international regime" refers to the "implicit and explicit principles, norms, rules and decision-making procedures around which actors" expectations converge in a given area of international relations' (Krasner, 1983). Thus, a regime is constituted by institutions. ${ }^{1}$

Generally speaking, a regime can be understood to be effective if it solves the problems it addresses (Haas et al., 1993; Young and Levy, 1999). Therefore, in order to assess effectiveness, a first step would be to determine whether the goals of the regime have been met (measuring the outcome) (Underdal, 1992). In the case of transboundary water, this could be done by measuring whether certain water quality targets have been met. However, it may often be difficult to measure the outcome of a regime; for instance, there may be a time lag between certain activities and changes in the environment. In this case, an initial approximation towards measuring effectiveness is to measure compliance (e.g. Chayes and Chayes, 1993), i.e. whether the respective actors ad-

\footnotetext{
${ }^{1}$ An analytical distinction is usually drawn between institutions and organizations, where organizations refer to the "players of the game" pursuing a common goal (North, 1990). This notwithstanding, organizations are also constituted by rules. Although they are constituted by rules, they also include the players pursuing certain goals.
} 
hered to the rules they set up and delivered the promised action (measuring output) (Underdal, 1992). However, compliance is not a sufficient condition for effectiveness, as a high level of compliance may not necessarily translate into a high level of effectiveness. As Downs et al. (1996) point out, it may often be easy for states to comply, as the respective international agreements do not ask them to make substantial contributions towards the cooperation problem.

Conversely, even if the respective goals have been met and the underlying problems solved, the question is still whether a causal link exists between the international regime and the respective outcome. The reason for this is that other (external) factors, such as measures taken at the national or subnational level - regardless of the international regime in place - or changes in production, may have contributed towards the achievement of the respective environmental goals. Therefore, we should treat institutional design and external factors separately in explaining regime outcomes.

Against this background, the so called Oslo-Potsdam solution for measuring effectiveness identifies two benchmarks against which the actual performance (AP) of an international regime can be measured: first, the collective optimum (CO) and, second, the no-regime counterfactual (NR), as illustrated in Fig. 1 (Underdal, 1992; Helm and Sprinz, 2000; Hovi et al., 2003).

The collective optimum (CO) may be defined in different ways (Young and Levy, 1999). It could be argued that the collective optimum is achieved if the respective goals are met. In addition, from an economic perspective, the collective optimum would be achieved if the net gains of cooperation were maximized (cost efficiency) or if certain goals were met at least cost (cost effectiveness). One could also ask if the goals are achieved in a fair manner (Bernauer, 1995; Young and Levy, 1999). From a methodological point of view, it will usually be more demanding to determine whether the respective goals are met in an efficient and fair manner than merely asking about goals achieved. In this study, we will assume that the goals set by the actors involved represent the "collective optimum", and for methodological reasons (especially the monetarization of the benefits of improved environmental conditions) we will refrain from conducting a cost-benefit analysis.

The no-regime counterfactual (NR) is the hypothetical state of the world that would have occurred if no regime had been put in place. In the language of game theory, it can be understood as the non-cooperative solution to an international cooperation problem that would follow from the uncoordinated choices of each actor's best reply to the strategies of the other actors (the so-called Nash solution). Measuring the no-regime counterfactual is particularly challenging. One way is to trace in depth the causal effects that led to actual performance. Another may be to build scenarios, starting with the state of the world that existed before the regime and asking what consequences would have flowed from the previous "rules of the game". A third strategy would be to

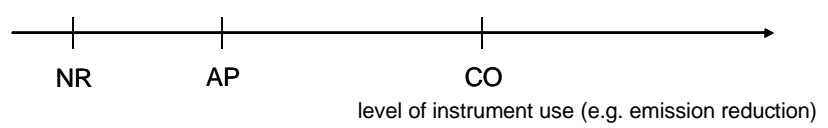

NR: no regime counter-factual

AP: actual performance

CO: collective optimum

Effectiveness score $E=(A P-N R) /(C O-N R)$

Fig. 1. Measuring Regime Effectiveness (after Helm and Sprinz, 2000:637).

study a large number of comparable cases with and without a regime in place. However, in the case of transboundary water management the latter strategy is likely to fail due to the fact that we are dealing with many explanatory variables and relatively few comparable cases. Therefore, in this study we will mainly follow the first strategy by tracing the causal relationships and by asking how the international regime contributed towards actual performance. Based on these relationships, values will be assessed for the no-regime counterfactual.

On the basis of actual performance (AP), the no-regime counterfactual (NR) and the collective optimum (CO), the effectiveness score $\mathrm{E}$ with $0 \leq \mathrm{E} \leq 1$ can be defined as indicated in Fig. 1. It allows the regime's actual contribution over and above what would have happened in the absence of the regime (AP-NR) to be placed in relation to its best possible contribution (CO-NR). A value of $\mathrm{E}$ close to 0 indicates a low level of effectiveness, whereas values of $E$ close to 1 indicate a high level of effectiveness. One advantage of $E$ is that it allows for a comparison of different international regimes.

\subsection{Databases and approach}

The analysis is based on two sources of information: first, relevant documents by the ICPE and, second, expert interviews. The ICPE not only produces publications about its action programs but also issues regular progress reports on their implementation, as well as other environmental and geographical background data. This information was reviewed and evaluated.

In addition, expert interviews were carried out. The interviews were of a semi-structured nature and were based on a standardized questionnaire. The interview partners were first asked to score the level of overall goal achievement and to explain their scores. In a second step, they were requested to score the achievement of objectives in the different areas of activity and to outline how the ICPE had contributed towards achieving the objectives, in order to assess the noregime counterfactual. In a third step, they were asked to assess the expediency of the institutional design. In this way, the information provided makes it possible to approach the 


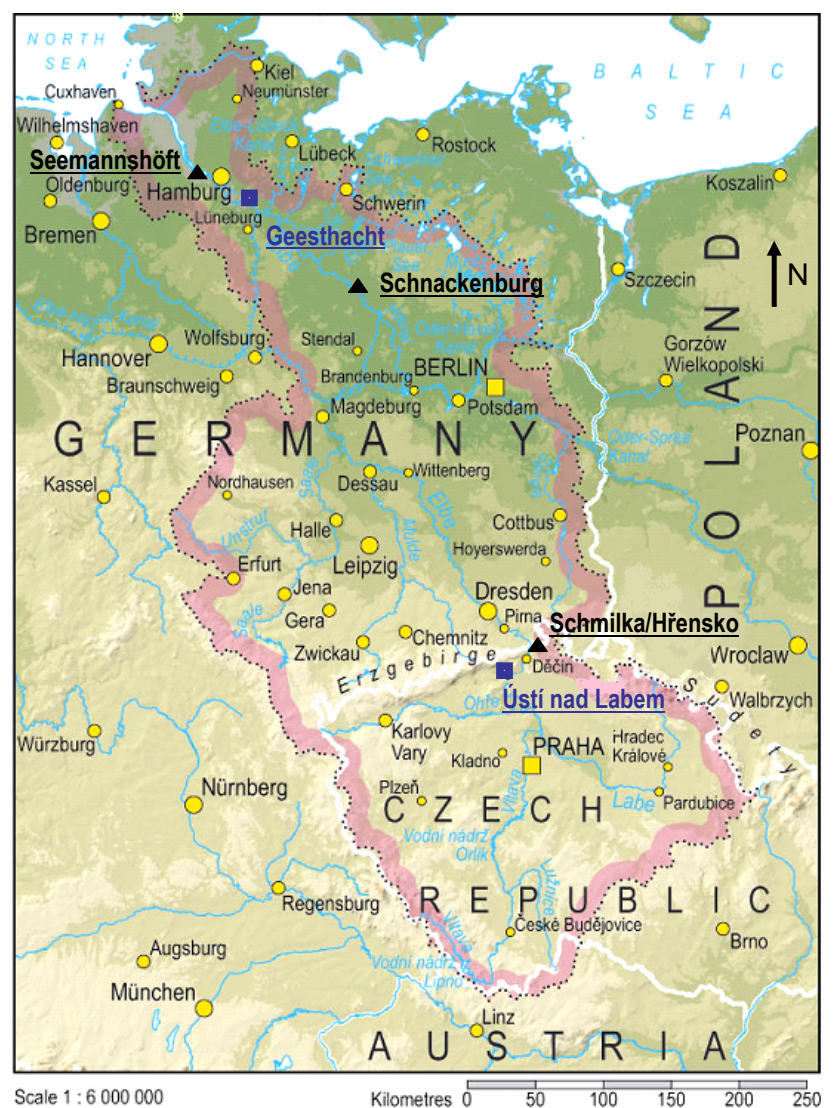

Fig. 2. Elbe River basin with main gauging stations (triangles) and fish passes (squares) (based on http://www.grid.unep.ch/product/ publication/freshwater_europe/images/map9.jpg (24 April 2007)).

question of institutional design from two angles: from the point of view of regime effectiveness, and through a direct evaluation of the institutional design.

In order to get "insider" views from the two riparian states, interviews were conducted with three representatives of the Czech and the German ICPE delegation respectively including heads of delegation or working groups, and members of the working groups on Action Programs and on Ecology, the main working groups in charge of the action programs. In addition, a representative of the ICPE Secretariat was interviewed. The Secretariat can be considered as a "neutral" insider with in-depth information on progress achieved. In addition to these insider perspectives, two German and one Czech representative of environmental NGOs were interviewed in order to gain an outsider view, as they had not been involved in the definition of the activities prior to 2004. In the Czech Republic it was possible only to identify one NGO representative dealing with transboundary waters. The person did not feel in a position to come up with scores, given that she had only recently become involved in the topic. By and large, only environmental NGOs have participated to date in activities related to the ICPE and the im- plementation of the EU Water Framework Directive in the Elbe Basin. Therefore, no representatives of the agricultural and industrial sectors were interviewed, as it is unlikely that they would have been able to contribute towards the scoring exercise. The interviews were fully transcribed and a content analysis carried out.

Thus, the study combined qualitative and quantitative methods. While a higher number of interviewees would have been desirable for the statistical analysis, the number was deliberately restricted in order to be able to carry out in-depth interviews; this made it possible, inter alia, to provide explanations of the scores provided. This was important for two reasons. First, it enabled the underlying causal relationships between institutional design and regime effectiveness to be identified. Second, the explanations provided by the interviewees allowed their scores to be interpreted - these scores, of course, are not only subjective and a matter of interpretation; different participants may also have had different motivations for influencing the scores in one way or another. Also, it appears that the number of individuals who are acquainted with the various components of the Action Programs is limited, so in that sense it is questionable whether it would have been possible to achieve a significantly higher number of substantiated expert scores.

\section{The Elbe water quality regime}

The Elbe River is shared by four countries: Germany, the Czech Republic, Austria and Poland. However, more than $99 \%$ of the basin area of 148268 square kilometers $\left(\mathrm{km}^{2}\right)$ is located in Germany and the Czech Republic, with shares of 65.5\% and 33.7\% respectively (IKSE, 2005a) (see Fig. 2). Within Germany, the river basin extends over ten of the sixteen German states (Länder).

Historically, the first issue that gave rise to transboundary cooperation in the Elbe river basin was navigation and maintenance of the river bed, the first treaty being signed in 1811 (McCaffrey, 2003). After the Second World War, waterrelated cooperation between West Germany on the one side and the German Democratic Republic and the Czechoslovak Socialist Republic on the other was largely inhibited by the cold war (Durth, 1996). At the same time, growing problems of pollution increased the tension between the riparian states. By the end of 1980s, the Elbe was one of the most heavily polluted rivers in Europe (IKSE, 1991b). The situation of non-cooperation changed rapidly after the fall of the Berlin wall and, as early as in October 1990, Czechoslovakia, the freshly reunited German Federal Republic and the European Community founded the International Commission for the Protection of the Elbe (ICPE). ${ }^{2}$

\footnotetext{
${ }^{2}$ Convention between the Federal Republic of Germany and the Czech and Slovak Federal Republic and the European Economic Community on the International Commission for the Protection of the Elbe, Magdeburg, 8 October 1990. After the rescission of the
} 
The convention aims at preventing the pollution of the Elbe and its drainage area, and at reducing North Sea pollution. It is explicitly not concerned with fisheries or navigation. The geographical scope of the ICPE extends across the drainage basin in the Czech Republic and Germany. The detailed objectives of the ICPE are:

1. to enable use to be made of the river, in particular for obtaining supplies of drinking water from bank-filtered waters and for agricultural use of the waters and sediments;

2. to achieve as natural an ecosystem as possible with a healthy diversity of species;

3. to reduce substantially North Sea pollution coming from the Elbe area.

In order to achieve these objectives, the ICPE prepared two action programs: the First Action Program (fast-track program) 1992-1995 (IKSE, 1991a), and the Elbe Action Program 1996-2010 (IKSE, 1995b). The First Action Program foresaw the construction of 139 sewerage treatment plants in the basin and a 30\% reduction in the concentration of 15 industrial priority substances. The 1995 Elbe Action Program comprised a comprehensive program of measures in seven areas of activity: (1) municipal wastewater treatment, (2) industrial wastewater treatment, (3) reduction of agricultural non-point pollution, (4) reduction of pollution from contaminated sites and landfills, (5) improvement of river continuity for fish migration, (6) establishment of protected areas and improvement of morphology, and (7) the prevention of accidental pollution. In addition, in 2003 the ICPE devised an Action Plan on Flood Control (IKSE, 2003a).

The organizational structure of the ICPE consists of:

- the Commission ( 3 delegations of up to 5 members each, plus experts) and its President;

- a Coordination Group;

- the Secretariat in Magdeburg tasked with preparing, implementing and supporting the commission's work; and

- different, changing Working Groups and Sub-Working Groups, consisting of delegates or experts appointed by each delegation.

IPCE decisions have to be unanimous. They are recommendations to the member states and are not legally binding (Epiney and Felder, 2002:82; Reinhardt and Caßor-Pfeiffer, 2006:17). Each party bears the costs of representation and

Slovak Republic in 1994, the members of ICPE were the Czech Republic, Germany and the European Community. With the accession of the Czech Republic to the European Union in May 2005, the European Union withdrew from the treaty. Austria and Poland have only observer status. They are, however, fully involved in ongoing efforts to implement the WFD in the basin. investigations on its own territory. The contributions to the costs of the secretariat are allocated as follows: Germany pays $65 \%$, the Czech Republic $32.5 \%$ and the EU 2.5\%. In order to monitor progress, the commission provides the parties with regular progress reports. No formal provisions exist for enforcement or dispute settlement.

\section{Measuring the effectiveness of the Elbe water quality regime}

\subsection{Achievement of overall goals}

\subsubsection{Achievement of ICPE target values}

In order to monitor the achievement of its goals, the ICPE has developed desirable target values for a list of priority substances. They are not legally binding on member states and there is apparently no temporal commitment by the member states to achieve these targets. They are used as an orientation to evaluate the status quo and, as suggested by one interviewee, were themselves the results of a bargaining process, representing compromise values.

The target values are being measured at the three gauging stations Schmilka/Hřensko on the Czech-German border, Schnackenburg on the former German-German border, and Seemannshöft in the delta area (see Fig. 2). No target values were specified for Goal 3, the protection of the North Sea. Depending on use, goal achievement is being measured for selected substances in the water or the sediment phase, as indicated in Table 1 (IKSE, 1998:7, Annex 2). It summarizes goal achievement for the year 2004 and lists problematic substances (IKSE, 2005b:25 and Annex 1).

With respect to Goal 1a - the use of Elbe water for drinking water production, fisheries and irrigation - the level of achievement is relatively high, as targets for 18 out of 26 priority substances were met at all three gauging stations. In addition, three of the eight substances above target, namely total nitrogen, total phosphorus and hexachlorbenzene, were close to target. Furthermore, Mercury, AOX and EDTA were only significantly above target at Seemannshöft, which appears to be a recent development. With respect to Goal $1 \mathrm{~b}$ - the use of Elbe sediments in agriculture - the level of achievement is low, as targets for only two of twelve substances were met at all three measuring stations. With respect to Goal 2 - the protection of aquatic ecosystems - only a minority of target values, both in the water and the sediment phase, were met at all three gauging stations. (In the water phase, two of the sixteen substances above target, namely chemical oxygen demand and nitrogen, were close to the target.)

Thus, it can be argued that on the basis of the ICPE indicators the level of goal achievement is relatively high with respect to Goal 1a, but further efforts will be needed to improve the quality of sediments for their use in agriculture (Goal 1b) 
Table 1. Achievement of overall goals.

\begin{tabular}{|c|c|c|c|c|}
\hline Goals & $\begin{array}{l}\text { 1a. Use of water for wa- } \\
\text { ter supply, fisheries \& irri- } \\
\text { gation }\end{array}$ & $\begin{array}{l}\text { 1b. Use of sediments in } \\
\text { agriculture }\end{array}$ & $\begin{array}{l}\text { 2. Protection of aquatic } \\
\text { eco-systems }\end{array}$ & 3. Protection of North Sea \\
\hline $\begin{array}{l}\text { ICPE target values } \\
\text { met in } 2004\end{array}$ & $\begin{array}{l}18 \text { of } 26 \text { in water phase } \\
(69 \%)\end{array}$ & $\begin{array}{l}2 \text { of } 12 \text { in sediment phase } \\
(17 \%)\end{array}$ & $\begin{array}{l}10 \text { of } 26 \text { in water phase } \\
(38 \%) \\
2 \text { of } 9 \text { in sediment phase } \\
(22 \%)\end{array}$ & Not specified \\
\hline $\begin{array}{l}\text { Problematic } \\
\text { substances }\end{array}$ & $\begin{array}{l}\text { CSB, (TOC), Hg, AOX, } \\
\text { EDTA }\end{array}$ & $\begin{array}{l}\mathrm{Hg}, \mathrm{Cd}, \mathrm{Zn}, \text { Tributyl-tin- } \\
\text { compounds, Hexachlorben- } \\
\text { zen \& AOX }\end{array}$ & $\begin{array}{l}\mathrm{Hg}, \mathrm{Cd}, \mathrm{Zn}, \mathrm{Cu}, \mathrm{As}, \\
\text { Tributyl-tin-compounds } \\
\text { Hexachlorbenzene, AOX, } \\
\text { EDTA }\end{array}$ & Not specified \\
\hline Avg. score & 7.3 & - & 6.3 & 6.5 \\
\hline $\begin{array}{l}\text { Coefficient of } \\
\text { variation }\end{array}$ & 0.23 & - & 0.23 & 0.24 \\
\hline $\begin{array}{l}\text { Explanations by } \\
\text { Interviewees }\end{array}$ & $\begin{array}{l}\text { Significant improvement of } \\
\text { the water quality has taken } \\
\text { place. } \\
\text { Consumption of larger } \\
\text { quantities of Elbe fish still } \\
\text { not advisable. } \\
\text { Drinking water rarely pro- } \\
\text { duced from Elbe water = } \\
\text { symbolic goal }\end{array}$ & $\begin{array}{l}\text { Some improvements, but } \\
\text { sediments can only be used } \\
\text { in the long run. } \\
\text { Old contaminants are (only) } \\
\text { remobilized and washed out } \\
\text { during floods. } \\
\text { Sediment use is not of prac- } \\
\text { tical relevance = symbolic } \\
\text { goal }\end{array}$ & $\begin{array}{l}\text { Good starting conditions at } \\
\text { Middle Elbe, due to low } \\
\text { regulation. } \\
\text { Ecosystems have benefited } \\
\text { from improved water qual- } \\
\text { ity vs. fish diversity has not } \\
\text { increased as expected and } \\
\text { only few fish species repro- } \\
\text { duce naturally }\end{array}$ & $\begin{array}{l}\text { Priority substances have de- } \\
\text { creased, but nutrient loads } \\
\text { are still too high for North } \\
\text { Sea. } \\
\text { North Sea was only added } \\
\text { for political reasons. }\end{array}$ \\
\hline
\end{tabular}

and to achieve a water and sediment quality that is satisfactory for the maintenance of aquatic ecosystems (Goal 2).

\subsubsection{Expert scores}

Given the difficulty of capturing complex goals using chemical indicators, the interview participants were asked in a second step to evaluate the achievement of the three goals on a scale of 0 to 10 and to explain their rating. Table 1 lists the average scores given in the interviews, the respective coefficients of variation, and the main explanations provided.

Overall, Goal 1a received the highest scores, with an average of 7.3, and Goal 2 the lowest, with an average of 6.3. The average score for Goal 3 was 6.5 . With respect to the scores, two main observations can be made. First, the scores differed significantly among the experts, as reflected by coefficients that varied between 0.23 and 0.24 . The reason can at least partly be found in their explanations, which indicate that the participants - at least sometimes - had different perceptions of what needed to happen in order to achieve the different goals.

Second, given the differences in the achievement of ICPE target values between Goal 1a and Goal 2 discussed in Sect. 4.1.1, it is interesting to note that the average scores for Goals 1a and 2 are not far apart from each other, with averages of 7.3 and 6.3 respectively. The participants were obviously more optimistic with regard to the level of achieve- ment of Goal 2 than one would have expected on the basis of the objective measurement. One possible explanation for this is that the state of ecosystems in the Middle Elbe in particular is generally considered to be quite satisfactory, despite a mediocre sediment quality. Another explanation is that the commission members did not want to score their achievements too poorly, although one NGO representative also gave a score of 7. It is also worth noting that none of the participants actually referred to the ICPE target values in their evaluations.

Based on the two assessments, it can be concluded that the level of achievement is fairly high with respect to human uses of the river water, but that the water and sediment quality still needs to be improved to allow for the reuse of sediments and to protect ecosystems and the North Sea. There is, however, some discrepancy between the indicator-based evaluation and the experts' evaluation of the state of the Elbe ecosystems, insofar as the experts were more optimistic with regard to the state of the aquatic ecosystems than one would have expected on the basis of the chemical analysis.

While overall the level of goal achievement may be considered to be medium to high, this does not yet explain whether the ICPE has actually contributed towards achieving these goals. Therefore, Sect. 4.2 will analyze compliance with the measures. 
Table 2. Compliance with measures.

\begin{tabular}{lll}
\hline Area of Activity & Summary of Progress Reports & $\begin{array}{l}\text { Level of Compliance (Au- } \\
\text { thor's evaluation based on } \\
\text { reports) }\end{array}$ \\
\hline 1. Municipal wastewater & $\begin{array}{l}\text { Virtually all planned WWTP completed or under way, } \\
\text { even before target. }\end{array}$ & Very high \\
\hline 2. Industrial point sources & $\begin{array}{l}\text { Proposed measures carried out: discharges of large in- } \\
\text { dustries regularly published; minimal requirements for }\end{array}$ & Very high \\
& different branches of industry defined. & \\
\hline $\begin{array}{l}\text { 3. Agricultural non-point } \\
\text { sources }\end{array}$ & $\begin{array}{l}\text { Recommendations on good practices made and moni- } \\
\text { toring of ongoing activities as planned. (Specific mea- }\end{array}$ & High \\
\hline sures were not foreseen.) & Relevant sites listed and rehabilitation measures mon- & High \\
and landfills & itored: 90\% of planned measures under way and 55\% & \\
\hline realized by end of 2002. & $\begin{array}{l}\text { Initial key measures realized. Ongoing; 25\% of planned } \\
\text { measures realized by 2004. }\end{array}$ & Low to medium (ongoing) \\
\hline 5. Fish migration & $\begin{array}{l}\text { Ongoing; 25\% of planned measures implemented by } \\
\text { end of 2002. Changing targets. }\end{array}$ & Low to medium (ongoing) \\
\hline morphology & $\begin{array}{l}\text { Proposed measures carried out: International Warning } \\
\text { and Alarm Plan agreed and updated; Elbe Alarm Model } \\
\text { operational; hazardous plants published; recommenda- }\end{array}$ & Very high \\
\hline tions on accident prevention made. & \\
\hline
\end{tabular}

\subsection{Compliance with action program measures}

In order to determine compliance with planned activities, it was analyzed whether the measures provided for in the First Action Program and the Elbe Action Program had actually been carried out. This analysis was based on the respective ICPE progress reports (IKSE, 1995a, 1998, 2000, 2003b, 2005b). The findings are summarized in Table 2.

In most areas of activity, the member states show high to very high levels of compliance. The only exceptions are fish migration, the delineation of protected areas and the improvement of river morphology, where the 2004 level of compliance can be considered as low to medium. However, it should be noted that activities in these areas are still ongoing until 2010.

Thus, overall the level of compliance can be considered to be high. However, this is not sufficient to indicate whether this actually contributed towards achieving the overall goals. Therefore, in Sect. 4.3 actual performance and the no-regime counterfactual will be assessed for each area of activity of the 1995 Elbe Action Program.

\subsection{The effectiveness of the Elbe Action Program}

In order to assess the current level of effectiveness of the Elbe Action Program (1996-2010), an attempt was made to come up with numerical values for the actual performance (AP) and the no-regime counterfactual (NR) in each area of activity; the effectiveness scores were then calculated on this basis.

\subsubsection{Actual performance}

In order to determine actual performance, the participants were asked to score the level of objective achievement in the different areas of activity. The average scores, the coefficients of variation and the main explanations provided are shown in Table 3.

Average scores are high (above 8) with respect to reducing pollution from municipal wastewater and preventing accidental pollution. This was somewhat expected, given the high level of compliance in these areas. But for most other areas as well, namely abatement of industrial pollution, delineation of protected areas, improvement of fish migration and abatement of pollution from contaminated sites, the average scores are fairly high, notwithstanding lower levels of compliance in some of them. The only area where the level of achievement is considered very low is the abatement of agricultural non-point pollution - despite high levels of compliance.

Much like the scores for the overall goals, the evaluations differed among the participants, although not as much as with 
Table 3. Areas of activity - experts' assessment and explanation of actual performance.

\begin{tabular}{|c|c|c|c|}
\hline Area of Activity & $\mathrm{AP}_{\mathrm{P}}$ & $\begin{array}{l}\text { Coefficient of } \\
\text { variation }\end{array}$ & Explanations by Interviewees \\
\hline 1. Municipal wastewater & 8.5 & 0.18 & $\begin{array}{l}\text { All planned WWTPs have been constructed vs. EU Ur- } \\
\text { ban Wastewater Directive not yet met vs. oversized in- } \\
\text { frastructure in East Germany (NGO statement). }\end{array}$ \\
\hline 2. Industrial point sources & 7.2 & 0.15 & $\begin{array}{l}\text { Main polluters targeted vs. smaller companies not yet } \\
\text { addressed vs. impact of minimal requirements unclear. }\end{array}$ \\
\hline $\begin{array}{l}\text { 3. Agricultural non-point } \\
\text { sources }\end{array}$ & 2.7 & 0.71 & $\begin{array}{l}\text { No improvement vs. some improvement due to decline } \\
\text { in agricultural production and EU directives/agricultural } \\
\text { policy. }\end{array}$ \\
\hline $\begin{array}{l}\text { 4. Contaminated sites } \\
\text { and landfills }\end{array}$ & 6.8 & 0.20 & $\begin{array}{l}\text { Progress with respect to sites listed vs. contamination in } \\
\text { tributaries remains high. }\end{array}$ \\
\hline 5. Fish migration & 6.8 & 0.13 & $\begin{array}{l}\text { Many priorities were implemented vs. progress in } \\
\text { Czech Republic limited to border area only; more to be } \\
\text { done in tributaries; morphology of main stem remains a } \\
\text { problem. }\end{array}$ \\
\hline $\begin{array}{l}\text { 6. Protected areas and } \\
\text { morphology }\end{array}$ & 7.4 & 0.13 & $\begin{array}{l}\text { Good progress under given framework conditions vs. } \\
\text { limited progress in Czech Republic. }\end{array}$ \\
\hline 7. Accidental pollution & 8.4 & 0.10 & $\begin{array}{l}\text { Very advanced alarm system and prediction model vs. } \\
\text { deficits in its application. }\end{array}$ \\
\hline
\end{tabular}

respect to overall goal achievement. For most areas of activity, the coefficient of variation of the respective scores is in the order of 0.1 to 0.2 , with the notable exception of the case of non-agricultural pollution, where the coefficient of variation is 0.7 . When analyzing the explanations provided, it becomes clear that the participants again used different reference points for their evaluation. A potential explanation is that the Elbe Action Program only specifies planned activities in each area of activity but does not explicitly state objectives. Hence, when asked to score the achievement of objectives in the various areas, some participants referred to the planned measures and others to the perceived overall objectives in the sector. In particular, in the case of agricultural non-point pollution, most commission members thought that some moderate progress had been made overall in the sector, while the NGO representatives gave scores of zero, as they did not see any impact by the ICPE.

Despite the relatively low number of experts interviewed, the differences in interpretation mentioned above, and the possibility that participants were biased in their assessments for the sake of illustration, the average scores will be used in the following to reflect the actual performance $\left(\mathrm{AP}_{\mathrm{P}}\right)$ of the Elbe Action Program on a scale from 0 to 10.
4.3.2 Specific ICPE contribution and no-regime counterfactual

In order to assess what would have happened if the ICPE had not been in place, the participants were asked to identify what the specific ICPE contribution had been in the different areas of activity. The findings are summarized in Table 4 and discussed below for the different areas of activity; these explanations are important for understanding how the ICPE works and how the institutional arrangements come into play.

In the area of reducing pollution from municipal wastewater, the main activities were the construction and extension of a list of priority wastewater treatment plants in the Elbe basin. It was argued that by defining an international list of priority actions, the ICPE facilitated access to EU and national funds in a situation where different economic sectors were competing for structural funds and other financial resources. Furthermore, the regular publication of progress reports by the ICPE created pressure on the respective administrations to report progress and thus to monitor implementation closely.

In order to reduce the discharge of priority substances from industries, lists of the emissions of major emitting industries were published regularly. Furthermore, minimal requirements were defined for the treatment of wastewater in different branches of industry. According to the interviewees, the main contribution made by the ICPE was the joint 
Table 4. Areas of activity - specific ICPE contribution.

\begin{tabular}{|c|c|c|c|}
\hline \multirow[t]{2}{*}{ Area of Activity } & \multirow[t]{2}{*}{$\mathrm{AP}_{\mathrm{P}}$} & \multicolumn{2}{|l|}{ Specific ICPE Contribution } \\
\hline & & Explanations by experts & Author's assessment \\
\hline 1. Municipal wastewater & 8.5 & $\begin{array}{l}\text { Priority lists } \rightarrow \text { access to funds } \\
\text { Monitoring } \rightarrow \text { stick to targets }\end{array}$ & Medium \\
\hline 2. Industrial point sources & 7.2 & $\begin{array}{l}\text { List of discharges of large emitters } \rightarrow \text { follow up by } \\
\text { administrations } \\
\text { Minimal requirements } \rightarrow \text { some influence on } \mathrm{CZ} \text { leg- } \\
\text { islation }\end{array}$ & Low to medium \\
\hline $\begin{array}{l}\text { 3. Agricultural non-point } \\
\text { sources }\end{array}$ & 2.7 & $\begin{array}{l}\text { Practically no contribution. } \\
\text { (Agenda-setting) }\end{array}$ & Zero \\
\hline $\begin{array}{l}\text { 4. Contaminated sites } \\
\text { and landfills }\end{array}$ & 6.8 & Priority lists, but little contribution, no priority area & Low \\
\hline 5. Fish migration & 6.8 & $\begin{array}{l}\text { Promoted ongoing activities, priority lists } \rightarrow \text { access } \\
\text { to Czech funds }\end{array}$ & Low to medium \\
\hline $\begin{array}{l}\text { 6. Protected areas and } \\
\text { morphology }\end{array}$ & 7.4 & Promoted ongoing activities, but no new proposals & Low \\
\hline 7. Accidental pollution & 8.4 & Original ICPE contribution & High \\
\hline
\end{tabular}

publication of the lists of major emitting industries. The idea was to point out the "bad guys", but to do it jointly rather than pitting one state against the other. Furthermore, the monitoring created pressure on administrations to identify and deal with the main dischargers in order to be able to report progress. It is unclear, however, to what extent the ICPE publications had a direct impact on these companies. Moreover, the impact of the definition of minimal requirements remains uncertain. In Germany, these standards applied anyway. Apparently they had some effect on the legislative process in the Czech Republic.

In order to reduce the discharge of nutrients and pesticides from non-point sources in agriculture, the member states compiled recommendations for good practice and for different types of measures. However, they did not commit themselves in the action program to carrying out specific activities on the ground. As such, the ICPE's impact remained negligible or minimal. The interviewees argued that the ICPE (and national governments) had no instruments to influence or control farmers. This notwithstanding, it was argued that it had been correct to include the abatement of agricultural non-point pollution in the Elbe Action Program and that the ICPE had contributed towards putting the topic on the agenda. Those who gave a higher score believed that some improvements had taken place, albeit due to other programs or measures.

The main ICPE activity with respect to the reduction of pollution from contaminated sites and landfills was to identify relevant sites and to monitor planned and ongoing reha- bilitation measures. The participants concurred that this was not a primary area of ICPE activity and that its contribution was minimal, being limited to prioritizing planned activities; however, it did not initiate any new activities.

In order to improve fish migration, the ICPE identified several measures to be implemented in Germany and the Czech Republic up to 2010. The first priorities were to realize fish passes at Geesthacht in Germany and at the weir Střekov at Ústí n.L. in the Czech Republic. While these and a few other measures have been realized, others being implemented in tributaries still need to be addressed. Overall, the ICPE contribution is seen as moderate. While several respondents believed that the ICPE contributed towards the realization of the fish pass in Geesthacht, another interviewee argued that it was mainly promoted by the ARGE Elbe, the working group of the German Länder on the Elbe. The completion of Geesthacht did, however, increase the pressure on the Czech Republic to move ahead with its program and, according to one interviewee, the first fish pass in the Czech Republic was built with "direct and indirect" support from the ICPE.

The ICPE also identified the potential for creating a number of protected areas, as well as several measures for improving the morphology of the river and its tributaries in the two countries. The accounting for these measures in the ICPE progress reports remains somewhat opaque. While major protected areas such as the UNESCO biotope reserve "River Landscape Elbe", which extends over 400 river kilometers, and the Czech national park, Bohemian Switzerland, were realized, other activities still need to be addressed. 
Table 5. Translating the qualitative assessments into quantitative weights.

\begin{tabular}{lc}
\hline Qualitative assessment & Quantitative weight (f) \\
\hline Zero & 0.00 \\
Low & 0.15 \\
Low to medium & 0.35 \\
Medium & 0.50 \\
Medium to high & 0.65 \\
High & 0.85 \\
Complete & 1.00 \\
\hline
\end{tabular}

Also, there is not much progress on morphology. According to the interviewees, activities were driven mainly by the states, but compiled and coordinated by the ICPE (such as the preparation of maps). They argued that the ICPE was the only institution adopting a basin-wide perspective, thus "putting local egoism into larger perspective". Again, this is believed to have accelerated the process. It was pointed out that in the Czech Republic, the opportunities were limited and it remained difficult to attribute activities to the ICPE or other factors.

In order to prevent accidental pollution, the ICPE developed an international warning and alarm plan and model, developed recommendations for accident prevention at company level and in flood-prone areas, and published a list of potentially hazardous plants. In general the interviewees agreed that this is an original activity area of transboundary water cooperation and that the contribution of the ICPE was high. However, some respondents pointed out that there might still be a certain gap between theory and practice. A cyanide accident at a company in the Czech Republic in January 2006 demonstrated problems in the application of the respective instruments by the company and within the Czech administration. On the other hand, there was successful prevention of an oil spill in the Czech Republic in March 2006.

On the basis of the explanations provided by the interviewees, the author sought to estimate the no-regime counterfactual $\left(\mathrm{NR}_{\mathrm{ID}}\right)$. In order to do so, in a first step a qualitative assessment of the level of the ICPE contribution towards actual performance $\mathrm{AP}_{\mathrm{P}}$ in the different areas of activity was carried out (Table 4). In a second step, each of the qualitative assessments was translated into a quantitative weight (f) on the basis of Table 5 . In a third step, the $\mathrm{NR}_{\mathrm{ID}}$ was calculated for each area of activity using $\mathrm{NR}_{\mathrm{ID}}=\mathrm{AP}_{\mathrm{P}}-\left(\mathrm{AP}_{\mathrm{P}} * \mathrm{f}\right)$ (see Table 6). The respective values of $\mathrm{NR}_{\mathrm{ID}}$ were calculated for the sake of illustration, their exact value depending, of course, on the respective weights.

\subsubsection{Effectiveness scores}

For the sake of illustration, the effectiveness scores $E_{i}$ for the different areas of activity within the 1995 Elbe Action Pro- gram were calculated as of the year 2005, using the average scores by the participants as actual performance $\left(\mathrm{AP}_{\mathrm{P}}\right)$ and the author's estimated no-regime counterfactual $\left(\mathrm{NR}_{\mathrm{ID}}\right)$ as a basis. In order to determine an overall effectiveness score $E_{\text {average }}$ the arithmetic average was formed on the basis of the individual effectiveness scores. ${ }^{3}$

Table 6 shows that the values of $E_{i}$ differ significantly among the different areas of activity, ranging between values of 0 and 0.82 . The effectiveness was high for the development of the international alarm plan and model $(\mathrm{E}=0.82)$ and the construction of municipal wastewater treatment plants $(E=0.74)$. The areas of the reduction of industrial pollution $(E=0.47)$, the improvement of river continuity for fish migration $(\mathrm{E}=0.43)$ and the establishment of protected areas $(E=0.30)$ show intermediate levels of effectiveness. The effectiveness of the ICPE was very low $(E=0)$ in the agricultural sector. The overall average effectiveness score of 0.43 indicates that the ICPE regime had some impact, but that the outcome can by no means be attributed to the ICPE alone. The interviewees argued that the ICPE mainly "speeded up" processes that would have happened at the national and subnational levels in any case, albeit at a slower speed. This applies in particular to the Czech Republic, where the process would have been significantly slower in the absence of the ICPE and where the ICPE contributed significantly towards active measures being undertaken. However, the water administration in the East German Länder also benefited from the ICPE process.

The question remains, though, how the differences in effectiveness can be explained. A frequent explanation is that it is easy for international water protection commissions to address point sources of pollution, but more difficult to address non-point sources of pollution (e.g. Gurtner-Zimmermann, 1998). The question is why this is so. Furthermore, the activities of the ICPE went beyond point and non-point sources of pollution. At a more general level, it can be argued instead that the effectiveness of the ICPE was particularly high when the main actors responsible for implementation were located within the public sector, such as in the case of the construction of municipal wastewater treatment plants or the development of the international alarm plan and model, and when specific visible infrastructure measures or projects were involved. By contrast, it appears that the effectiveness was relatively low where the behavior of non-state actors needed to be influenced. This applies in particular to the agricultural sector, a general problem for international river protection commissions in Europe (see, for instance, Gurtner-

\footnotetext{
${ }^{3}$ Alternatively, given that the interviewees themselves emphasized that the different areas of activity played different roles, a weighted average could be considered as well. Given that at least some of the areas with lower effectiveness scores, such as the rehabilitation of contaminated sites and landfills, were not a priority area of activity, a weighted average would increase the effectiveness score.
} 
Table 6. Calculating no-regime counterfactuals and effectiveness scores for the Elbe Action Program.

\begin{tabular}{lcclccc}
\hline Area of Activity & APP & $\mathrm{CO}$ & \multicolumn{2}{c}{ ICPE Contribution } & $\mathrm{NR}_{\mathrm{ID}}$ & $\mathrm{E}_{\mathrm{i}}$ \\
& & & qualitative & quantitative (f) & & \\
\hline 1. Municipal wastewater & 8.5 & 10 & Medium & 0.50 & 4.3 & 0.74 \\
2. Industrial point sources & 7.2 & 10 & Low to medium & 0.35 & 4.7 & 0.47 \\
3. Agricultural non-point sources & 2.7 & 10 & Zero & 0.00 & 2.7 & 0.00 \\
4. Contaminated sites \& landfills & 6.8 & 10 & Low & 0.15 & 5.8 & 0.24 \\
5. Fish migration & 6.8 & 10 & Low to medium & 0.35 & 4.4 & 0.43 \\
6. Protected areas \& morphology & 7.4 & 10 & Low & 0.15 & 6.3 & 0.30 \\
7. Accidental pollution & 8.4 & 10 & High & 0.85 & 1.3 & 0.82 \\
\hline Average & 6.8 & 10 & & & 4.2 & 0.43 \\
\hline
\end{tabular}

Zimmermann, 1998 for the Rhine). In contrast, industry appears to constitute an intermediary case, where public administration has some influence through standard setting and the publication of data on emissions. In the areas of improvement of river continuity for fish migration and the setting up of protected areas, the ICPE also promoted "visible" projects; however, it can be assumed that the ICPE was somewhat less influential in these areas, as the decision-making process on these measures tends to involve more stakeholders and to be more complex than in the area of municipal wastewater treatment.

Overall, it should be reiterated that the quantitative findings are indicative only given the limited number of interviews that where possible, given the relatively high variation among the scores provided by the interviewees and given the uncertainties associated with quantifying the no-regime counterfactual by the author. This notwithstanding, the effectiveness analysis on the basis of the Oslo-Potsdam solution reveals very clearly that (1) the level of influence of the ICPE and its contribution was lower than one would perhaps have assumed on the basis of the analysis of overall goal achievement alone, and (2) - even more importantly - that the effectiveness varied significantly among the different areas of activities. While this was implicit in the qualitative analysis of the ICPE's specific contribution, the effectiveness score made it possible to relate the ICPE's actual contribution (AP-NR) to its assumed best possible contribution (CO-NR).

\section{Explaining the outcome of the Elbe water quality regime}

In the following, an attempt will be made to explain the outcome described in Sect. 4. This section builds upon the material presented in Sect. 4 and on additional information obtained in the interviews, including the experts' evaluation of the expediency of the institutional arrangements. It is clear from the no-regime counterfactual analysis in Sect. 4 that the overall outcome can only partly be explained by the existence of the ICPE regime. Therefore, alongside the institutional set-up (Sect. 5.1) other explanatory variables have also to be taken into account (Sect. 5.2).

\subsection{ICPE approach and role of the institutional set-up}

The general working mechanism of the ICPE can be summarized as follows:

1. The ICPE provided a forum for identifying priority action from a "basin" perspective. In doing so, a stepby-step approach was pursued, in analogy to the Rhine basin, which started with the main priorities (hot spots), and sought to refine the targets once the primary objectives had been achieved (given that Austria and Poland did not participate, about $99 \%$ of the entire basin area was considered). The prioritization process was carried out by the ICPE working groups in which representatives and experts from the respective governments met. This ensured that the recommendations were developed by those who were responsible for their implementation. The secretariat supported the working groups in the preparation of documents. In this way, the secretariat fulfilled an important editorial function, while also having the opportunity to input ideas into the process. Furthermore, the work of the working groups was backed up by high level political commitment to the international objectives. This was important for the working groups in order to be able to move forward. The identification of priorities for action from a basin perspective - one goal being the protection of the North Sea - implied an acknowledgment by both upstream and downstream riparians that they were jointly responsible for contributing towards the clean-up of the river. Thus, the hydrologically induced upstream-downstream problem was transformed into a more symmetrical problem requiring collective action. Furthermore, the prioritization process also ensured that the goal of protecting the North Sea was achieved at least (or low) cost. 
2. Implementation of agreed measures took place at national or sub-national levels. The fact that the implementation of agreed measures was carried out at national level had several advantages. It allowed the respective administration to follow their usual procedures and minimized international coordination costs. It also implied that each party bore its own costs. At the same time, the national water administrations used their international obligations to promote their interests within the administration and to increase their access to funds, including national and various EU funds. Typically, different sectors compete for these funds, and the international obligations helped the parties to increase their share.

3. The ICPE monitored implementation of measures by regularly publishing progress reports on the internet, which effectively served as an enforcement mechanism. The ICPE is responsible for monitoring implementation, but it does not have a formal sanctioning mechanism in place. This is of interest, given that from a game-theoretical perspective, a sanctioning mechanism is necessary to sustain cooperation in Prisoner's Dilemma-like situations (e.g. Dombrowsky, 2007a). However, as the interviewees argued, the fact that the ICPE regularly published progress reports created pressure on the national administrations to follow up on implementation in order to be able to report on progress. It can be argued that the progress reports increased the accountability of the ICPE vis-à-vis the general public and, as such, provided not only a monitoring but arguably also an enforcement mechanism that generated an incentive to pursue implementation. The interviewees also argued that, at least at the international level, a sanctioning mechanism had not been necessary and could even have been counter-productive, as it could have undermined the building of trust between the two countries. This notwithstanding, some interviewees expressed the sentiment that at times they had wished they had stronger enforcement mechanisms in place at the national level, in particular vis-à-vis industry and agriculture.

4. A conscious attempt was made to build trust. At the level of informal institutions, a conscious attempt was apparently made to establish good relationships and trust. In general, the working atmosphere was considered good to excellent, and at the working group level in particular even friendships emerged over time. Two factors were mentioned that promoted the building of trust. First, both a Czech and a German representative mentioned that a special effort was made by the German side not to dominate the process. The Czech representative remarked that "the German colleagues very sensitively and in harmony with our effort agreed on the steps how to increase" (Czech interview partner 2). The
German representative emphasized that it had been important to make it clear that the other side was not being put down (German interview partner 1). Second, NGOs were only granted observer status in 2004 in the context of implementation of the EU Water Framework Directive. Two German interview partners argued that the fact that NGOs did not participate from the beginning had also contributed towards building trust among the representatives from the two countries.

Overall, the above shows that the ICPE's institutional structure and the way the work was approached have to be seen as closely interrelated. In general, the interviewees believed that the institutional structure "stood the test". In response to the question of what could have been improved with regard to the institutional set-up, two aspects were mentioned. First, some argued that some working groups, such as the ones on Monography and Law and Procedures, had not necessarily been needed. The main activity of the working group on Law had been to organize observer status for Poland and Austria. Furthermore, the working group on Research was by and large limited to work in Germany. Thus, the structure could have been leaner and, as such, more efficient.

Second, there appears to have been an issue with the socalled coordination group. It consisted of the President and the chairpersons of the various working groups. It usually met once a year in between plenary sessions. While some thought that this was actually needed, others argued that it existed only on paper. What was lacking, according to this latter fraction, was a group to coordinate the activities of the different working groups at a working level. In the absence of such a group, this gap was filled by and large by the working group on Action Programs. However, this had led to some tensions with other working groups, as they did not want to be coordinated by a peer group, but to report directly to the Commission. Some argued that the working group on Action Programs did not necessarily have a steering function, but it had the last say, as it took up the results of the other working groups in order to present them in a way that could be sold to the public.

Thus, on the basis of the interviewees' assessments and the above explanations, it can be argued that, apart from the fact that the efficiency of the institutional arrangements could perhaps have been slightly improved, the ICPE work approach and institutional structure was generally adequate and allowed the ICPE to promote ongoing and planned national activities effectively, at least with respect to point sources of pollution and large visible projects. In doing so, the main factors were (1) a careful division of labor between the international and national levels in terms of priority setting, implementation and monitoring, and (2) a conscious attempt to build trust. At the same time, while the above provides explanations for how the approach worked, establishing a direct causality between institutional structure and specific outcomes remains challenging. 


\subsection{Additional explanatory variables}

\subsubsection{Upstream and downstream had incentives to cooper- ate}

In an upstream-downstream setting the question is whether the upstream country has any incentive to cooperate (e.g. LeMarquand, 1997; Marty, 2001; Dombrowsky, 2007a). In the case of the Elbe, it can be argued that both the Czech Republic as the upstream country and Germany as the downstream country had sufficient incentives to cooperate, and that this was an important precondition for achieving the outcome that has been brought about. In the interviews, the following reasons were mentioned for cooperation on the Czech side: an interest in good relationships more generally and access to Western markets, both of which entail working on environmental matters; the perceived international pressure to improve the quality of the Elbe water; and, from 1994 onwards, the aspiration towards EU accession. Thus, Czech aspirations for greater integration with the West can be seen as a major motivation for cooperating on environmental matters. Or, to put it the other way around, water quality should not stand in the way of broader good relations. Furthermore, in 1994 the Czech Republic started official negotiations with the European Union about its accession, formally joining the EU in May 2005. Thus, from 1994 on it was clear that activities in the framework of the ICPE would also contribute towards the fulfilling the EU requirements in the water sector. While according to the Czech interviewees EU accession did not play a role from the beginning, it did so at least since 1994.

While German interviewees presumed that there had also been internal pressure to improve water quality, the Czech representatives had not really perceived any public demand for this. However, they all emphasized that there had been a tradition of river basin planning in the Czech Republic, so that the logical next step was to extend the river basin approach to the international level. Hence, going beyond direct incentives, ideas and convictions apparently also played a role, at least at the level of the Czech delegation members. In addition, German interviewees argued that the Czech commission members were also able to use the international obligations to promote their own administration's interests internally and to increase their standing within the administration. One German interview partner concluded that overall "the Czech Republic cooperated because it was in its own interest, not because it wanted to do something good for Germany. Otherwise there would have been more calls for financial contributions" (German interview partner 2).

Germany, of course, had an inherent interest in cooperating, as it benefited from pollution control upstream; however, it also played its part: "Hamburg of course also did what it demanded to be done upstream." (German interview partner 2 ). Furthermore, it was argued that German defection from the project would have undermined its credibility. In addi- tion, as one Czech interviewee mentioned, the goal to protect the North Sea provided direct incentives for Germany. Internal pressure within Germany to clean up the river was not explicitly mentioned as an argument, but it too can be expected to have played a role. There was also a commitment to the polluter-pays principle, and Germany was also obliged, of course, to fulfill EU regulations.

\subsubsection{Cooperation took place under favorable framework conditions}

The second external explanation for why the countries were relatively successful is that cooperation took place under favorable framework conditions. First, the interviewees emphasized that once cooperation became possible after the fall of the Iron Curtain, there was real enthusiasm and the political will to move quickly. The high political will to address the problems was reflected by the fact that the ICPE treaty was negotiated within nine months and signed five days after German reunification. Thus, the fall of the Berlin wall provided a "window of opportunity".

Second, the partial breakdown of industrial production in the former German Democratic Republic - and partly also in the Czech Republic - contributed significantly towards an improvement in the quality of the Elbe water. This is an important external factor that explains the relatively high level of goal achievement for goal 1a.

Third, an important prerequisite for the implementation of measures was the availability of funds. In this context, different types of EU funds played a role. One interview partner argued: "Both countries were able to use the ICPE to direct EU funds into the water sector. In the absence of such EU funds, cooperation might be difficult to achieve" (German interview partner 2).

Fourth, given that the middle stretch of the Elbe is much less regulated than other European rivers, the achievement of comparatively healthy eco-systems in this section of the river was much less challenging than, for instance, in the Czech Republic or on the Rhine.

Fifth, a Czech interview partner also pointed out the fact that the officials and experts working with each other all had a high and balanced level of professionalism. Thus, technical capacity on both sides was high, which in turn facilitated dialogue.

\subsubsection{Factors inhibiting cooperation}

In response to the question of which factors inhibited success, the limited ability to control industry and agriculture along with complexities at the national level were mentioned (see above).

In other contexts it was mentioned that there were sometimes cultural differences as well, e.g. in terms of addressing conflicts directly or dealing with information flows, but this was also perceived as a generational problem. Furthermore, 
the absence of a common working language was perceived by some as a problem. Others thought that they had managed quite well even with poor English, and apparently the situation is changing as younger people join the process. The fact that all staff members of the secretariat need to be bilingual was perceived as very helpful in facilitating communication.

Overall, it can be concluded that despite a certain language barrier there were no major factors inhibiting international cooperation. Instead, factors hampering effectiveness lie in the limited ability of the commission members to influence complex domestic policy processes.

\section{Conclusions}

In order to learn more about the design of adequate institutions for transboundary water management, this paper analyzed the role of institutional design in the outcomes of water quality and ecology-related work carried out by the International Commission for the Protection of the Elbe.

The study pursued a mixed methodological approach that included both qualitative and quantitative elements. In general, it can be argued that the quantitative approach of the Oslo-Potsdam solution for measuring effectiveness provided analytical clarity and contributed towards showing the different levels of effectiveness in the different areas of activity. At the same time, the qualitative approach contributed towards a better understanding of the causal relationships. Given that the number of interviews remained comparatively small, the quantitative results are indicative only.

Overall, the paper shows that the countries were relatively successful in achieving their overall goals. While the ICPE generally showed a high level of compliance, one main finding is that the ICPE's contribution towards achieving the goals varied significantly among the different areas of activity, and that much would also have been achieved in its absence. The ICPE's contribution was greatest where the main responsibility for action lay with the public authorities, such as in the area of wastewater treatment and the establishment of an international alarm plan and model. Its contribution was practically zero in the reduction of non-point pollution from agriculture, where success depended on the behavior of individual private actors (farmers). It was intermediate where multiple parties were involved in the decision-making process, such as in the area of fish migration or the establishment of protected areas.

The commission supported the countries' activities by serving as a forum for the identification of priority action from a basin perspective. The resulting international obligations increased the power of participating national administrations and their access to funds. At the same time, the Commission's reporting to the public served as an enforcement mechanism. In this way, the ICPE speeded up implementation, in particular in the Czech Republic. At the informal level, cooperation was fostered by the fact that the stronger party made a conscious effort not to dominate the process. Overall, the institutional set-up and work approach can thus be considered to be conducive to problem solving, at least with regard to specific "visible" projects undertaken by the public administrations.

The relatively positive outcome was also supported by favorable framework conditions, in the sense that not only downstream but - on account of broader economic interests - upstream too had an interest in cooperating. Furthermore, the fall of the Berlin wall generated a high level of political will to improve the situation. In addition, both countries benefited from access to external EU funds.

Overall, it can be argued that the Rhine model of transboundary cooperation was replicated successfully in the Elbe basin. Furthermore, it appears that the economic inequality in the Elbe basin, with the upstream party being the economically weaker party, promoted rather than inhibited cooperation. The Czech Republic's desire to achieve greater integration with Western Europe clearly increased its incentive to cooperate. At the same time, in both the Rhine and the Elbe basins, the general work approach of setting basin-wide priorities, national level implementation and international monitoring was conducive to problem solving and hence applies to conditions of economic equality and downstreamupstream dominance alike.

The question is: under what conditions does the ICPE/ICPR model become transferable? It certainly becomes so for upstream-downstream and arguably also for border water quality conflicts where all parties recognize the need to protect downstream lakes or regional seas. Furthermore, the approach is most powerful when the responsibility for such activities lies with actors in the public sector. The question is whether it also applies to situations where the upstream party - or the party appropriating the resource first is economically more powerful and where water quantity or water regulation issues are at stake. But still, in procedural terms, the idea of a forum for problem solving and the apparent attempts to build trust might be of wider applicability.

Acknowledgements. The research that forms the basis of this paper was carried out in the framework of the German-Israeli-Palestinian research project "From conflict to collective action: Institutional change and management options to govern transboundary watercourses", co-funded by the German and Israeli Ministries of Science (BMBF/MOST). I thank my interview partners for their time and insights. Furthermore, I would like to thank S. Barles, S. Möllenkamp and two anonymous referees for valuable comments.

Edited by: S. Barles 


\section{References}

Barrett, S.: Conflict and Cooperation in Managing International Water Resources, Policy Research Working Paper 1303, Washington, DC, The World Bank, 1994.

Bernauer, T.: Explaining Success and Failure in International River Management, Aquat. Sci., 64, 1-19, 2002.

Bernauer, T.: The Effect of International Environmental Institutions: How We Might Learn More, Int. Organ., 49(2), 351-377, 1995.

Bernauer, T.: Managing International Rivers, in: Global Governance: Drawing Insights from the Environmental Experience, edited by: Young, O. R., Cambridge, MA, The MIT Press, 155195, 1997.

Bernauer, T. and Moser, P.: Reducing Pollution of the Rhine River: The Influence of International Cooperation, Journal of Environment and Development, 5(4), 389-415, 1996.

Chayes, A. and Chayes, A.: On Compliance, Int. Organ., 47(2), 175-205, 1993.

Dinar, S.: Assessing Side-payments and Cost-sharing Patterns in International Water Agreements: The Geographic and Economic Connection, Polit. Geogr., 25, 412-437, 2006.

Dombrowsky, I.: Revisiting the Potential for Benefit-sharing the Management of Transboundary Rivers, Water Policy, accepted, 2007a.

Dombrowsky, I.: Conflict, Cooperation and Institutions in International Water Management. An Economic Analysis, Cheltenham UK and Northampton, MA, USA, Edward Elgar, 2007b.

Dombrowsky, I.: Water Accords in the Middle East Peace Process: Moving towards Co-operation?', in: Security and the Environment in the Mediterranean. Conceptualising Security and Environmental Conflicts, edited by: Brauch, H. G., Marquina, A., Selim, M., Liotta, P. H., and Rogers, P., Berlin, Springer-Verlag, 729-744, 2003.

Downs, G., Rocke, D. M., and Barsoom, P.: Is the Good News about Compliance Good News about Cooperation?, Int. Organ., 50(3), 379-406, 1996.

Durth, R.: Grenzüberschreitende Umweltprobleme und regionale Integration, Zur Politischen Ökonomie von Oberlauf-UnterlaufProblemen an internationalen Flüssen, Baden-Baden, Nomos, 1996.

Edig, A. v.: Die Nutzung internationaler Wasserressourcen: Rechtsanspruch oder Machtinstrument? Die Beispiele des Jordans und der israelisch-palästinensischen Grundwasservorkommen, Baden-Baden, Nomos, 2001.

Epiney, A. and Felder, A.: Überprüfung internationaler wasserwirtschaftlicher Übereinkommen im Hinblick auf die Implementierung der Wasserrahmenrichtlinie, UBA Texte 17/02, Berlin, Umweltbundesamt, 2002.

Espey, M. and Towfique, B.: International Bilateral Water Treaty Formation, Water Resour. Res., 40, W05S05, doi:10.1029/2003WR002534, 2004.

Fischhendler, I.: When Ambiguity in Treaty Design Becomes Destructive: A Study of Transboundary Water, Global Environmental Politics, accepted, 2007.

Fischhendler, I., Feitelson, E., and Eaton, D.: The Short-term and Long-term Ramifications of Linkages Involving Natural Resources: the US-Mexico Transboundary Water Case, Environ. Plann. C, 22, 633-650, 2004.

Gleditsch, N. P., Owen, T., Furlong, K., and Lacina, B.: Conflicts over Shared Rivers: Resource Wars or Fuzzy Boundaries, Polit. Geogr., 25(4), 361-382, 2006.

Gleick, P. H.: Water and Conflict: Fresh Water Resources and International Security, Int. Security, 18, 79-112, 1993.

Gurtner-Zimmermann, A.: The effectiveness of the Rhine Action Program: methodology and results of an evaluation of the impacts of international cooperation, Int. Environ. Affair., 10, 241266, 1998.

Haas, P. M., Keohane, R. O., and Levy, M. A. (Eds.): Institutions for the Earth. Sources of Effective International Environmental Protection, Cambridge, MA, The MIT Press, 1993.

Helm, C. and Sprinz, D.: Measuring the Effectiveness of International Environmental Regimes, J. Conflict Resolut., 44(5), 630652, 2000.

Holtrup, P.: Der Schutz grenzüberschreitender Flüsse in Europa zur Effektivität internationaler Umweltregime, Programmgruppe Technologieforschung Kenn-Nr. Jül-3642 D 5 (Diss. Universität Bonn), Jülich, Forschungszentrum Jülich, 1999.

Hovi, J., Sprinz, D., and Underdal, A.: The Oslo-Potsdam Solution to Measuring Regime Effectiveness: Critique, Response, and the Road Ahead, Global Environmental Politics, 3(3), 74-96, 2003.

IKSE: Erstes Aktionsprogramm (Sofortprogramm) zur Reduzierung der Schadstofffrachten in der Elbe und ihrem Einzugsgebiet, Magdeburg, Internationale Kommission zum Schutz der Elbe, 1991a.

IKSE: Gewässergütebericht Elbe 1989 von der Quelle bis zur Mündung, Hamburg, Magdeburg, Internationale Kommission zum Schutz der Elbe, 1991b.

IKSE: Abschlußbericht über den Stand der Durchführung der im "Ersten Aktionsprogramm (Sofortprogramm) zur Reduzierung der Schadstofffrachten in der Elbe und ihrem Einzugsgebiet" enthaltenen Maßnahmen, Magdeburg, Internationale Kommission zum Schutz der Elbe, 1995a.

IKSE: Aktionsprogramm Elbe, Magdeburg, Internationale Kommission zum Schutz der Elbe, 1995b.

IKSE: Erster Bericht über die Erfüllung des "Aktionsprogramm Elbe", Magdeburg, Internationale Kommission zum Schutz der Elbe, 1998.

IKSE: Zweiter Bericht über die Erfüllung des “Aktionsprogramm Elbe" im Zeitraum 1998 und 1999, Magdeburg, Internationale Kommission zum Schutz der Elbe, 2000.

IKSE: Aktionsplan Hochwasserschutz Elbe, Magdeburg, Internationale Kommission zum Schutz der Elbe, 2003a.

IKSE: Dritter Bericht über die Erfüllung des "Aktionsprogramm Elbe" im Zeitraum 2000 bis 2002, Magdeburg, Internationale Kommission zum Schutz der Elbe, 2003b.

IKSE: Die Elbe und ihr Einzugsgebiet. Ein geographischhydrologischer und wasserwirtschaftlicher Überblick, Magdeburg, Internationale Kommission zum Schutz der Elbe, 2005a.

IKSE: Vierter Bericht über die Erfüllung des "Aktionsprogramm Elbe" im Zeitraum 2003 bis 2004, Magdeburg, Internationale Kommission zum Schutz der Elbe, 2005b.

Krasner, S. D. (Ed.): Structural Causes and Regime Consequences: Regimes as Intervening Variables, in: International Regimes, Ithaca, Cornell University Press, 1-22, 1983.

LeMarquand, D. G.: International Rivers. The Politics of Cooperation, Vancouver, Westwater Research Center, University of British Columbia, 1977.

Lindemann, S.: Water Regime Formation in Europe: A Re- 
search Framework with Lessons from the Rhine and Elbe River Basins, FFU-rep 04-2006, Paper prepared for the GermanIsraeli-Palestinian research project "From conflict to collective action: Institutional change and management options to govern transboundary watercourses", Berlin, Forschungsstelle für Umweltpolitik Freie Universität Berlin, 2006.

Marty, F.: The Management of International Rivers - Problems, Politics and Institutions, Frankfurt, Peter Lang, 2001.

McCaffrey, S.: The Law of International Watercourses. NonNavigational Uses, Paperback Edition, Oxford, Oxford University Press, 2003.

Möllenkamp, S.: The "WFD-Effect" on Upstream-Downstream Relations in International River Basins - Insights From the Rhine and the Elbe Basins, Hydrol. Earth Syst. Sci. Discuss., 4, 14071428, 2007, http://www.hydrol-earth-syst-sci-discuss.net/4/1407/2007/.

North, D. C.: Institutions, Institutional Change and Economic Performance, Cambridge, Cambridge University Press, 1990.

Rangeley, R., Thiam, B. M., Andersen, R. A., and Lyle, C. A.: International River Basin Organizations in Sub-Saharan Africa, World Bank Technical Paper No. 250, Washington, DC, The World Bank, 1994.

Reinhardt, M. and Caßor-Pfeiffer, S.: Analysis of the Role of Law to Initiate and Govern Change of Formal and Informal Water Management Institutions in Europe and Their Legal Structure, Paper prepared for the German-Israeli-Palestinian research project: "From conflict to collective action: Institutional change and management options to govern transboundary watercourses", University of Trier, Faculty of Law - Public Law, 2006.

Rogers, P.: The Value of Cooperation in Resolving International River Basin Disputes, Nat. Resour. Forum, 17(May), 117-131, 1993.
Sadoff, C. W. and Grey, D.: Beyond the River: The Benefits of Cooperation on International Rivers, Water Policy, 4, 389-403, 2002.

Song, J. and Whittington, D.: Why Have Some Countries on International Rivers Been Successful Negotiating Treaties? A Global Perspective, Water Resour. Res., 40, W05S06, doi:10.1029/2003WR002536, 2004.

Underdal, A.: The Concept of Regime "Effectiveness", Cooperation and Conflict, 27, 227-240, 1992.

UNEP: Atlas of International Freshwater Agreements, Nairobi, United Nations Environment Programme, 2002.

Verweij, M.: Transboundary Environmental Problems and Cultural Theory. The Protection of the Rhine and the Great Lakes, Hampshire, UK, Palgrave, 2000.

Waterbury, J.: Transboundary Water and the Challenge of International Cooperation in the Middle East, in: Water in the Arab World: Perspectives and Prognoses, edited by: Rogers, P. and Lydon, P., Cambridge, MA, Harvard University Press, 39-64, 1994.

Wolf, A. T.: Conflict and Cooperation along International Waterways, Water Policy, 1, 251-265, 1998.

Wolf, A. T., Yoffe, S. B., and Giordano, M.: International Waters: Identifying Basins at Risk, Water Policy, 5, 29-60, 2003.

Young, O. R. and Levy, M. A.: The Effectiveness of International Environmental Regimes, in: The Effectiveness of International Environmental Regimes. Causal Connections and Behavioral Mechanisms, edited by: Young, O. R., Cambridge, MA, The MIT Press, 1-32, 1999.

Zeitoun, M. and Warner, J.: Hydro-hegemony - A Framework for the Analysis of Trans-boundary Water Conflicts, Water Policy, 8(5), 435-460, 2006. 